\title{
Progresso do oídio em função da fenologia do cajueiro
}

\author{
Marlon Vagner Valentim Martins ${ }^{1}$, Joilson Silva Lima ${ }^{2}$, José Emilson Cardoso ${ }^{1}$, \\ Francisco Marto Pinto Viana ${ }^{1}$, Márcio Akio Ootani ${ }^{3}$
}

${ }^{1}$ Embrapa Agroindústria Tropical, Rua Dra. Sara Mesquita, 2270, 60110-511, Fortaleza, CE, Brasil. ${ }^{2}$ Instituto Federal de Educação, Ciência e Tecnologia do Ceará - IFCE, 62042-030, Sobral, CE, Brasil. ${ }^{3}$ Universidade Federal do Ceará - UFC, 60455-900, Fortaleza, CE, Brasil.

Autor para correspondência: Marlon Vagner Valentim Martins (marlon.valentim@embrapa.br)

Data de chegada: 06/10/2016. Aceito para publicação em: 26/09/2017.

$10.1590 / 0100-5405 / 170270$

\section{RESUMO}

Martins, M.V.V.; Lima, J.S.; Cardoso, J.E.; Viana, F.M.P.; Ootani, M.A. Progresso do oídio em função da fenologia do cajueiro. Summa Phytopathologica, v.44, n.2, p.178-184, 2018.

O oídio (Pseudoidium anacardii) reduz quantitativa e qualitativamente a produção do cajueiro em diferentes regiões do Brasil. Severas epidemias ocorrem com frequência, iniciando-se durante a floração e se estendendo até o final do ciclo de produção da planta. O progresso da doença está relacionado à densidade de inóculo na área com cajueiros, aos fatores ambientais e à suscetibilidade dos órgãos para a infecção. Face a inexistência de informações sobre a epidemiologia dessa doença, objetivou-se caracterizar o progresso do oídio do cajueiro-anão em função da fenologia da planta. Foram aplicados seis tratamentos correspondentes aos períodos de proteção fenológica, com a aplicação de fungicida à base de enxofre, para quantificar a severidade do oídio nas panículas em duas floradas sucessivas. A partir dos dados coletados, foram geradas curvas de progresso da doença ajustadas a modelos lineares. O modelo Monomolecular foi o que melhor se ajustou às curvas de progresso do oídio nas panículas nas épocas I e II na ausência de proteção com enxofre. No modelo Monomolecular as taxas de progresso do oídio foram maiores na época I em relação à época II. Por outro lado, o modelo Logístico apresentou o melhor ajuste quando se introduziu o enxofre para proteger as panículas e reduzir a epidemia. Para maiores períodos de proteção, não foi possível ajustes de modelos em função da baixa severidade do oídio. É possível utilizar o modelo Monomolecular para estimar a taxa de doença e, o atraso do início da epidemia está diretamente relacionado ao aumento da proteção das panículas.

Palavras-chave: Anacardium occidentale; Pseudoidium anacardii; modelos epidemiológicos

\section{ABSTRACT}

Martins, M.V.V.; Lima, J.S.; Cardoso, J.E.; Viana, F.M.P.; Ootani, M.A. Powdery mildew progress according to cashew phenology. Summa Phytopathologica, v.44, n.2, p.178-184, 2018.

Powdery mildew (Pseudoidium anacardii) quantitatively and qualitatively decreases cashew production in different regions of Brazil. Severe epidemics are frequent, starting during flowering and extending to the end of the plant production cycle. The disease progress is related to the inoculum density in the area with cashew trees, to the environmental factors and to the susceptibility of the plant organs to infection. Given the lack of information on the epidemiology of this disease, the present study aimed to characterize powdery mildew progress in dwarf cashew trees according the plant phenology. Six treatments corresponding to the phenological protection periods were used, including the application of sulfur fungicide to quantify powdery mildew severity in two successive flowering stages. The collected data were used to generate disease progress curves adjusted to linear models. The Monomolecular model best fit to the powdery mildew progress curves for the panicles in periods I and II in the absence of protection with sulfur. According to the Monomolecular model, powdery mildew progress rates were greater in period I compared to period II. On the other hand, the Logistic model showed the best fit when sulfur was introduced to protect the panicles and reduce the epidemics. For longer periods of protection, the models could not be fit due to the low severity of powdery mildew. The Monomolecular model can be used to estimate the disease progress rate, and the delay in the beginning of the epidemics is directly related to the increase in the protection of panicles.

Keywords: Anacardium occidentale; Pseudoidium anacardii; Epidemiologic models

O cajueiro (Anacardium occidentale L) é afetado por diferentes problemas fitossanitários que interferem na sua produção (7). Os danos são em termos quantitativos pela diminuição da produção de castanhas e pedúnculos e qualitativos quando interferem diretamente no desenvolvimento e no aspecto comerciável desses órgãos, principalmente quanto se trata do consumo do pedúnculo in natura. Muitas doenças afetam o cajueiro, mas atualmente o oídio [(Pseudoidium anacardii (F. Noack) U. Braun \& R.T.A. Cook)] (3) é o principal problema (5). Devidos aos danos causados, o controle da doença deve ser adotado precocemente antes do início da epidemia. A epidemia inicia quando o hospedeiro emite as floradas e se estende durante todo o ciclo de produção da planta com menores taxas observadas nas floradas seguintes. O pico de doença, nas condições do semiárido nordestino, ocorre principalmente no primeiro fluxo de floração, influenciado pelo ambiente, pela agressividade do patógeno e pela suscetibilidade do cajueiro. Os botões e as flores das panículas são os órgãos mais suscetíveis à infecção $(11,19)$, mas constatam-se infecções após essa fase, tanto no pedúnculo quanto na castanha na fase de maturi (fruto jovem do cajueiro). Apesar de registrada em várias regiões do Brasil, a doença é mais frequente na região Nordeste, ocorrendo durante toda floração do cajueiro, cuja incidência pode atingir 100\% quando não há intervenções com produtos químicos (6). A severidade da doença, 
baseada no comportamento do fungo em condições epidêmicas, pode ser caracterizada por curvas de progresso. Desse modo, a obtenção de modelos que expliquem o progresso da doença em função do tempo pode ser útil para estimar a doença e as tomadas de decisão para o manejo (4). Não existem estudos epidemiológicos do oídio do cajueiro no Brasil e os que existem são direcionados ao controle químico da doença (6). Portanto, o objetivo desse trabalho foi caracterizar o progresso do oídio do cajueiro em função da fenologia da planta durante duas épocas sucessivas de floração do clone de cajueiro-anão BRS 189, considerado o mais suscetível à doença.

\section{MATERIAL E MÉTODOS}

Os experimentos foram desenvolvidos no período compreendido entre o início de junho a novembro de 2015 no campo experimental da Embrapa Agroindústria Tropical, sediado em Pacajus, CE, em uma área cultivada com o clone de cajueiro-anão, BRS 189, com 168 plantas em idade produtiva, no espaçamento de $7 \mathrm{~m}$ x $6 \mathrm{~m}$, em 0,8 ha. As plantas foram podadas mecanicamente (podadeira tratorizada) em abril de 2015 para a emissão de brotações novas. Os tratos culturais, como adubação, controle de plantas indesejadas e pragas, foram realizados de acordo com o sistema de produção para a cultura. Em ambos os experimentos, os tratamentos da época I (19/06/2015) e da época II (31/08/2015) correspondente ao fluxo de floração da planta, foram distribuídos em blocos inteiramente casualisados com quatro repetições sendo cada parcela constituída de uma planta com dez panículas (composta de botões e flores) marcadas ao redor de toda a copa da planta com o mesmo padrão de desenvolvimento. Imediatamente após o início da florada, as panículas foram etiquetadas em sequência de 1 a 10 , para facilitar a avaliação da doença. Nas épocas I e II foram utilizados, respectivamente, seis tratamentos relacionados aos períodos (dias) de proteção fenológica das panículas com enxofre: T6 - sem proteção (testemunha); T5 - proteção por 14 e 21 dias; T4 - proteção por 21 e 28 dias; T3 - proteção por 28 e 35 dias; T2 - proteção por 35 e 42 dias; T1- proteção por 42 a 49 dias.

Em todos os tratamentos, com exceção da testemunha, foi utilizada uma calda fungicida a base de enxofre (1g Kumulus ${ }^{\circledR} / \mathrm{L}$ de água + Tween $80 \%$ a $0,05 \%$ ) pulverizada semanalmente sobre as panículas até o ponto de escorrimento, sempre no período da manhã, por meio de um pulverizador manual com pressão prévia PCP - 1P Guarany ${ }^{\mathbb{R}}$, com capacidade de $1,25 \mathrm{~L}$.

A severidade do oídio nas panículas (botões e flores) foi avaliada semanalmente, utilizando-se notas de 0 a 4 de acordo com Sijaona (21). Os dados médios de severidade da doença em proporção foram submetidos aos ajustes das curvas de progresso da doença linearizadas de acordo com os modelos Logístico $\mathrm{y}=1 /\left(1+\mathrm{e}^{-\ln (\mathrm{y} / 1-\mathrm{y})}\right)$, Monomolecular $y=1-e^{-\ln (1 / 1-y)}$ e Gompertz $y=\exp \left(-e^{\ln (-\ln (y)}\right)$, tendo o tempo como variável independente e o modelo escolhido foi baseado no maior coeficiente de determinação $\left(\mathrm{R}^{2}\right)$, menor quadrado médio do resíduo (QMR) e ausência de dispersão de resíduo. Utilizou-se a "back transformation" dos dados para a previsão da proporção de severidade correspondente de acordo com a equação de regressão obtida dos modelos epidemiológicos (4). Os valores da taxa de progresso do oídio dos modelos significativos nas duas épocas foram submetidos ao teste-t, a $5 \%$ de probabilidade.

\section{RESULTADOS}

As curvas de progresso da doença nas panículas permitiram detectar o efeito dos períodos de proteção na severidade do oídio. Atrasos no início da epidemia produziram diferentes curvas de progresso da doença e, de acordo com os tratamentos foram ajustados alguns modelos que representaram as epidemias (Tabelas 1 e 2).

Nas panículas submetidas ao tratamento $\mathrm{T} 1$, a doença não progrediu com a passar do tempo e não foi possível gerar modelos nessa relação em ambas às épocas. Nas panículas do tratamento T2, onde a proteção com enxofre foi exercida durante 35 e 42 dias, respectivamente, nas épocas I e II, a doença foi detectada apenas na última avaliação. Porém, não foi possível estabelecer relação entre doença e tempo devido à baixa severidade do oídio nas panículas. Por outro lado, à medida que os períodos de proteção com o enxofre diminuíram, houve maiores progressos da doença. Fato constatado nas panículas dos tratamentos T3, T4 e T5, onde as epidemias iniciaram, respectivamente, aos 42, 35 e 28 dias, na época I e aos 49, 42 e 35 dias na época II (Figuras 1 e 2).

Ajustes mais significativos aos modelos epidemiológicos foram obtidos em função da precocidade da epidemia. Nas panículas protegidas com enxofre, apenas os tratamentos T4 e T5 foram mais adequados em gerar os modelos epidemiológicos (Tabelas 1 e 2). $\mathrm{Na}$ época I, o tratamento T4 se ajustou aos modelos epidemiológicos Logístico e Gompertz que apresentaram, respectivamente, coeficiente de determinação de 0,72 e 0,73 (Tabela 1). A mesma situação ocorreu na época II, onde estes mesmos modelos foram os que melhor representaram a epidemia do oídio (Tabela 2). No tratamento T5, todos

Tabela 1. Equação de regressão, coeficiente de determinação ajustado $\left(\mathbf{R}^{2 *}\right)$ e taxa de progresso da doença (r) de modelos epidemiológico ajustados aos tratamentos com enxofre na primeira época da floração do cajueiro-anão BRS 189.

\begin{tabular}{|c|c|c|c|c|c|c|}
\hline \multirow[b]{2}{*}{ Modelo } & \multicolumn{6}{|c|}{ Época I } \\
\hline & $\mathrm{T} 1$ & $\mathrm{~T} 2$ & T3 & $\mathrm{T} 4$ & T5 & T6 \\
\hline $\mathbf{R}^{2^{*}}$ & & 0,36 & 0,56 & 0,72 & 0,80 & 0,60 \\
\hline $\mathbf{r}$ & & 0,12 & 0,19 & 0,25 & 0,27 & 0,13 \\
\hline Monomolecular & - & $\mathrm{Y}=0,0001 \mathrm{x}^{\mathrm{ns}}-0,0018$ & $Y=0,0002 x^{*}-0,0038$ & $Y=0,0006 x^{*}-0,0074$ & $Y=0,0009 x^{*}-0,0084$ & $Y=0,0009 x^{*}-0,0054$ \\
\hline $\mathbf{r}$ & & 0,0001 & 0,0002 & 0,0006 & 0,0009 & 0,0009 \\
\hline Gompertz & - & $\mathrm{Y}=0,01 \mathrm{x}^{\mathrm{ns}}-2,82$ & $Y=0,02 x^{*}-2,92$ & $Y=0,03 x^{*}-2,96$ & $Y=0,03 x^{*}-2,83$ & $Y=0,02 x^{*}-2,03$ \\
\hline $\mathbf{R}^{2^{*}}$ & & 0,36 & 0,56 & 0,73 & 0,84 & 0,73 \\
\hline $\mathbf{r}$ & & 0,01 & 0,02 & 0,03 & 0,03 & 0,02 \\
\hline
\end{tabular}


Tabela 2. Equação de regressão, coeficiente de determinação ajustado $\left(\mathbf{R}^{2^{*}}\right)$ e taxa de progresso da doença (r) de modelos epidemiológico ajustados aos tratamentos com enxofre na segunda época da floração do cajueiro-anão BRS 189.

\begin{tabular}{|c|c|c|c|c|c|c|}
\hline & & & & Época II & & \\
\hline Modelo & $\mathrm{T} 1$ & $\mathrm{~T} 2$ & T3 & $\mathrm{T} 4$ & T5 & T6 \\
\hline $\mathbf{R}^{2^{*}}$ & & 0,25 & 0,55 & 0,70 & 0,80 & 0,52 \\
\hline $\mathbf{r}$ & & 0,07 & 0,14 & 0,19 & 0,22 & 0,13 \\
\hline Monomolecular & - & $\mathrm{Y}=0,00006 \mathrm{x}^{\mathrm{ns}}-0,0012$ & $Y=0,0002 x^{*}-0,0037$ & $Y=0,0004 x^{*}-0,0069$ & $Y=0,0006 x^{*}-0,0086$ & $Y=0,0007 x^{*}-0,0004$ \\
\hline $\mathbf{r}$ & & 0,0012 & 0,0002 & 0,0004 & 0,0006 & 0,0007 \\
\hline Gompertz & - & $\mathrm{Y}=0,008 \mathrm{x}^{\mathrm{ns}}-2,77$ & $\mathrm{Y}=0,01 \mathrm{x}^{*}-2,92$ & $Y=0,02 x^{*}-2,97$ & $\mathrm{Y}=0,02 \mathrm{x}^{*}-2,91$ & $Y=0,02 x^{*}-2,15$ \\
\hline $\mathbf{R}^{2^{*}}$ & & 0,25 & 0,55 & 0,70 & 0,83 & 0,65 \\
\hline $\mathbf{r}$ & & 0,008 & 0,01 & 0,02 & 0,02 & 0,02 \\
\hline
\end{tabular}

os três modelos representaram o progresso da doença nas duas épocas. Os modelos Logísticos, Monomolecular e Gompertz apresentaram coeficiente de determinação de $0,80,084$ e 0,84 na época I e 0,80, 0,80 e 0,83 na época II, respectivamente (Tabelas 1 e 2). Nestes dois tratamentos nas duas épocas, foi possível estimar a doença correspondente ao registrado no campo (Figuras 1 e 2).

$\mathrm{Na}$ ausência de controle da doença, os dados de progresso do oídio se ajustaram significativamente ao modelo Monomolecular. Esse modelo apresentou, respectivamente, coeficiente de determinação $\left(\mathrm{R}^{2^{*}}\right)$ de 0,90 e 0,92 nas épocas I e II (Tabelas 1 e 2). Foi possível estimar a doença correspondente ao registrado no campo quando se utilizou o modelo Monomolecular (Figuras 1J e 2J). As curvas representativas das epidemias nas duas épocas estudadas foram semelhantes. Nas panículas do tratamento T6, onde não houve proteção com o enxofre, à epidemia iniciou rapidamente aos sete dias do inicio da florada nas duas épocas (Figuras 1 e 2).

Tabela 3. Teste $t$ da taxa de severidade do oídio obtida pelo modelo Logístico ajustado aos tratamentos T5 e T4 na primeira e segunda época da floração do cajueiro-anão BRS 189.

\begin{tabular}{lcc}
\hline T5 & ÉPOCA I & ÉPOCA II \\
\hline Média (r) & 0,2765 & 0,22075 \\
Variância & $4,56667 \mathrm{E}-05$ & $1,15833 \mathrm{E}-05$ \\
Valor- $P$ & $0,00012342^{*}$ & \\
\hline T4 & & \\
\hline Média (r) & 0,2545 & 0,19125 \\
Variância & $7,23333 \mathrm{E}-05$ & 0,000274917 \\
Valor- $P$ & $0,002458777^{*}$ & \\
\hline ÉPOCA I & T5 & T4 \\
\hline Média (r) & 0,2765 & 0,2545 \\
Variância & $4,56667 \mathrm{E}-05$ & $7,23333 \mathrm{E}-05$ \\
Valor- $P$ & $0,006722109^{*}$ & \\
\hline ÉPOCA II & & \\
\hline Média (r) & 0,22075 & 0,19125 \\
Variância & $1,15833 \mathrm{E}-05$ & 0,000274917 \\
Valor- $P$ & $0,0398906^{*}$ & \\
\hline * Valores significativos a $P \leq 0,05$. &
\end{tabular}

* Valores significativos a $P \leq 0,05$.
Considerando os tratamentos T4 e T5, selecionou-se o modelo Logístico que se ajustou melhor à epidemia em campo. Nesse caso, com uma aplicação a mais de fungicida, a taxa do progresso do oídio (r) nas panículas que receberam o tratamento T4 foi estatisticamente inferior $(r=0,25)$ que a taxa do T5 $(r=0,27)$ na época $I$. Na época II, o r do tratamento T4 foi igual a 0,19 e a do tratamento T5 igual a 0,22 , evidenciando o efeito significativo da aplicação de enxofre na redução da taxa de progresso da doença (Tabela 3). Por outro lado, quando se obteve a taxa de progresso da doença baseada no modelo Monomolecular, não houve diferença significativa entre as taxas de progresso da doença nas panículas submetias aos tratamentos T6 e T5 na época I. Para a época II, as taxas não foram iguais, sendo a do tratamento T6 superior a do tratamento T5 (Tabela 4). Independente da proteção com enxofre (tratamentos T5 e T4) e sem proteção (tratamento T6), as taxas de progresso registradas na época I foram significativamente superiores das registradas na época II (Tabelas 3 e 4).

Tabela 4. Teste $\mathrm{t}$ da taxa de severidade do oídio obtida pelo modelo Monomolecular ajustado aos tratamentos T6 e T5 na primeira e segunda época da floração do cajueiro-anão BRS 189.

\begin{tabular}{lcc}
\hline T6 & ÉPOCA I & ÉPOCA II \\
\hline Média (r) & 0,000967 & 0,0007605 \\
Variância & $1,14667 \mathrm{E}-10$ & $5,39 \mathrm{E}-10$ \\
Valor- $P$ & $0,0000859^{*}$ & \\
\hline T5 & & \\
\hline Média (r) & 0,0009125 & 0,0006385 \\
Variância & $4,785 \mathrm{E}-09$ & $6,23767 \mathrm{E}-09$ \\
Valor- $P$ & $0,001976957^{*}$ & \\
\hline ÉPOCA I & T6 & T5 \\
\hline Média (r) & 0,000967 & 0,0009125 \\
Variância & $1,14667 \mathrm{E}-10$ & $4,785 \mathrm{E}-09$ \\
Valor- $P$ & $0,217294712^{\text {ns }}$ & \\
\hline ÉPOCA II & & 0,0006385 \\
\hline Média (r) & 0,0007605 & $6,23767 \mathrm{E}-09$ \\
Variância & $5,39 \mathrm{E}-10$ & \\
Valor- $P$ & $0,041388809^{*}$ &
\end{tabular}

* Valores significativos a $P \leq 0,05$. 

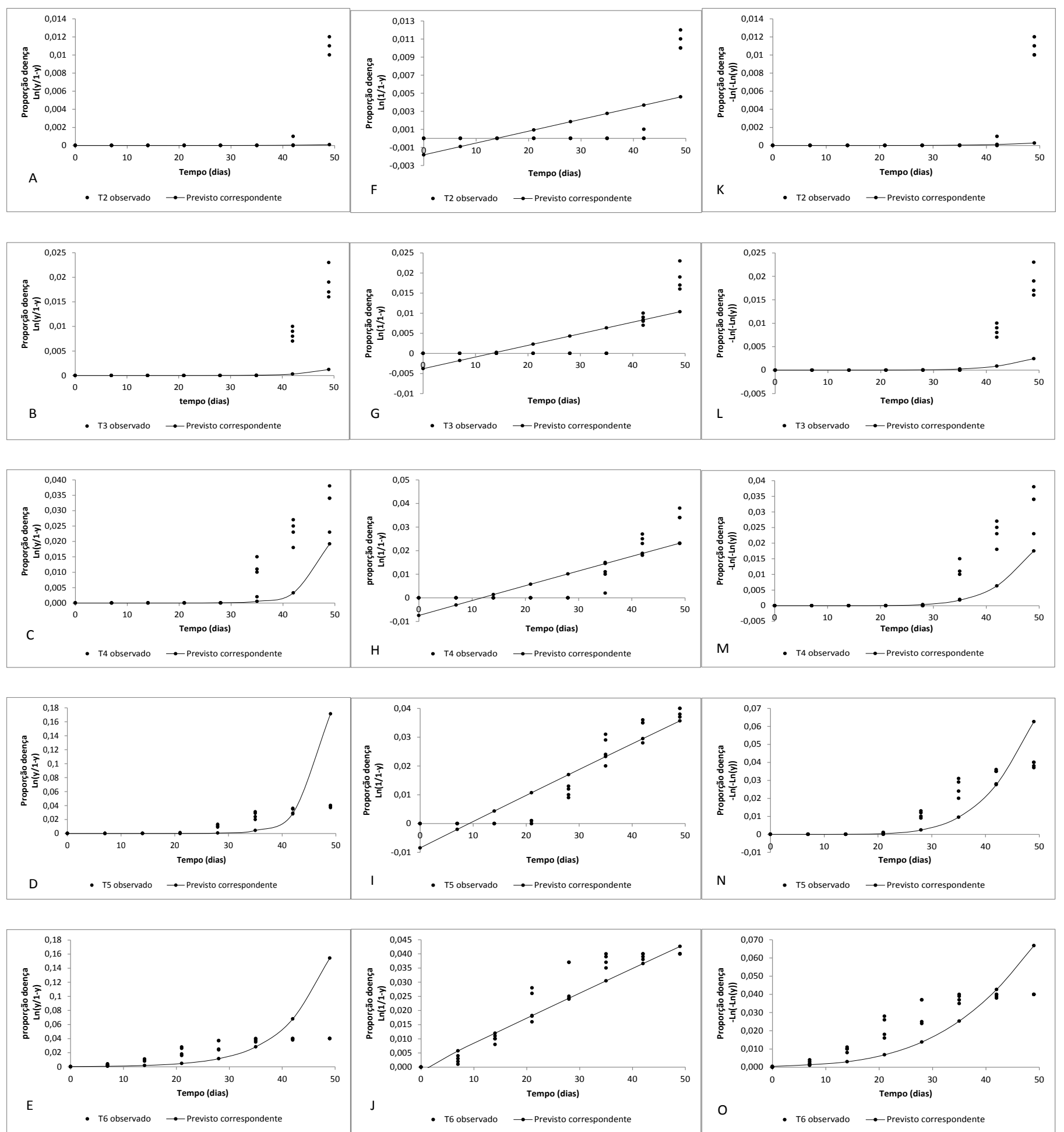

Figura 1. Curvas de progresso da doença ajustadas aos modelos epidemiológicos na época I. A, B, C, D e E (Modelo Logístico). F, G, H, I e J (Modelo Monomolecular). K, L, M, N e O (Modelo Gompertz) para os tratamentos 2, 3, 4, 5 e 6, respectivamente. Pontos significam valores de proporção de severidade do oídio nas panículas observados em campo. A linha cheia representa os ajustes da proporção de doença correspondente ao valor real observado no campo.

\section{DISCUSSÃO}

O estudo da epidemia do oídio forneceu informações relevantes para o manejo da doença no campo. As curvas de progresso revelaram o potencial do oídio em causar infecções precoces nas panículas do cajueiro na ausência de controle e de se expandir a taxas elevadas até atingir o pico máximo de doença. Estes resultados estão de acordo com Shomari \& Kennedy (18), que observaram rápido progresso da doença nas panículas do cajueiro, tanto dentro quanto fora da copa das plantas, em diferentes regiões da Tanzânia. 

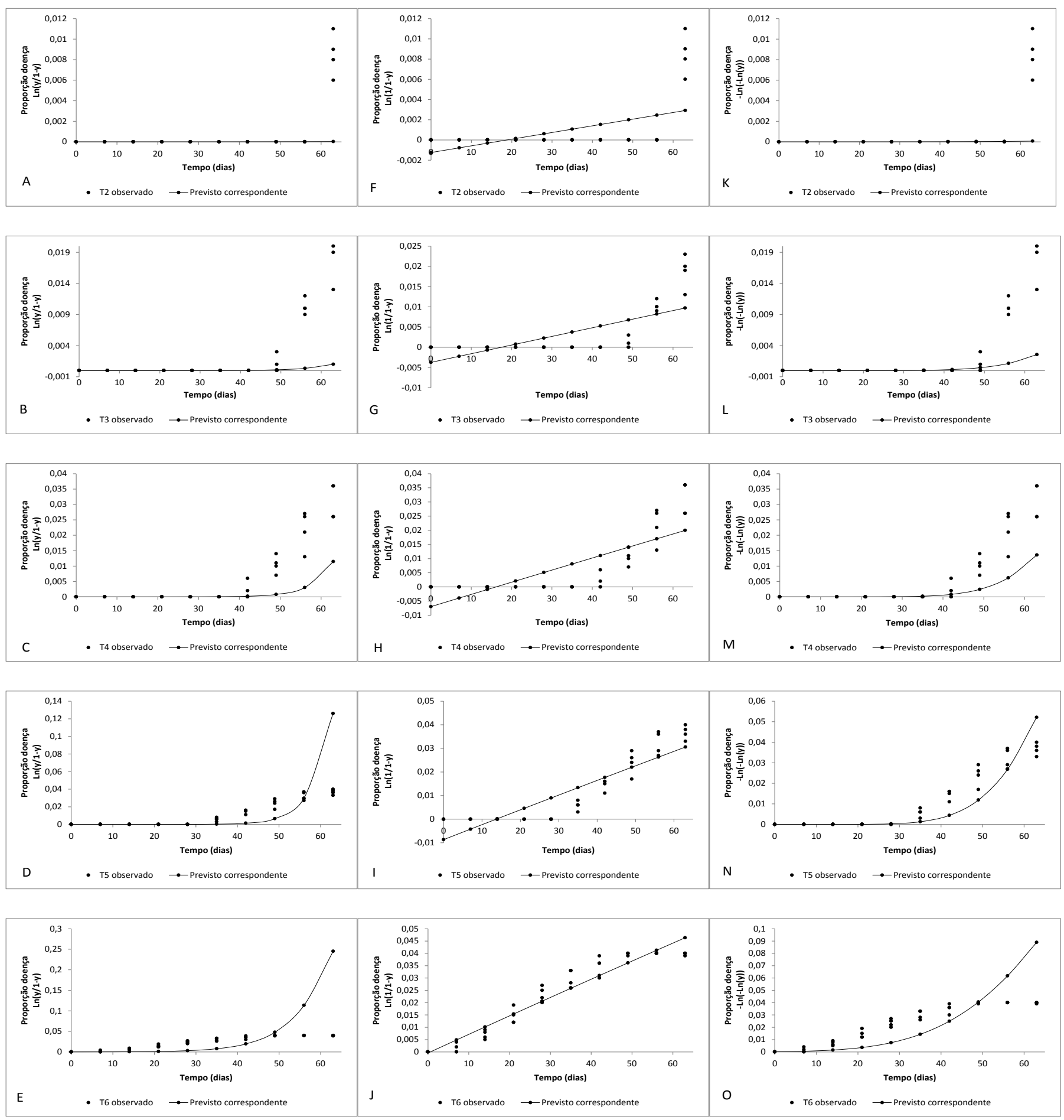

Figura 2. Curvas de progresso da doença ajustadas aos modelos epidemiológicos na época II. A, B, C, D e E (Modelo Logístico). F, G, H, I e J (Modelo Monomolecular). K, L, M, N e O (Modelo Gompertz) para os tratamentos 2, 3, 4, 5 e 6, respectivamente. Pontos significam valores de proporção de severidade do oídio nas panículas observados em campo. A linha cheia representa os ajustes da proporção de doença correspondente ao valor real observado no campo.

Não foi possível avaliar a influência direta da umidade relativa e da temperatura no progresso da doença. Considerando que a umidade relativa média, na época I $(78 \%)$ foi ligeiramente superior àquela registrada na época II (74\%), supõe-se que provavelmente essa diferença não foi determinante para distinguir as taxas de progresso do oídio ocorridas nestas épocas. Por outro lado, observações realizadas em laboratório sobre o efeito da temperatura na germinação dos conídios do oídio (9) fazem pressupor que a temperatura pode ter um papel mais efetivo que a umidade relativa na redução da taxa de progresso da doença entre as épocas. Shomari \& Kennedy (18) constataram que a variação da umidade relativa teve pequeno efeito sobre a germinação dos conídios de $P$. anacardii, porém, temperaturas superiores a $30^{\circ} \mathrm{C}$ influenciaram 
negativamente a germinação dos conídios. Para outros patossistemas do grupo dos oídios, na maioria das vezes a temperatura exerce papel mais importante que a umidade relativa interferindo diretamente na germinação dos conídios e consequentemente na infecção $(8,23)$. Além disso, Aust \& v. Hoyningen-Huene (1) relataram que nas epidemias de oídios não se deve considerar o efeito do microclima apenas sobre o patógeno, mas também sobre o hospedeiro. Neste caso, o clone de cajueiro-anão BRS 189 apresentou significativa influência na epidemia, principalmente pela sua precocidade que coincide com o clima mais favorável ao seu desenvolvimento e ao ataque do oídio.

A doença, causada pelo fungo $P$. anacardii, aumentou continuamente na ausência de manejo e o progresso do oídio se ajustou ao modelo epidemiológico Monomolecular. Este modelo, geralmente é ajustado às doenças monocíclicas e àquelas que exigem longos períodos de incubação para exibir os sintomas $(2,22)$, não correspondendo ao apresentado pelo oídio do cajueiro. Por outro lado, outros modelos podem ser ajustados quando práticas adotadas no manejo interferem no progresso de doenças (10). Fato evidenciado quando iniciou a proteção com enxofre, a partir do tratamento T5, onde o modelo Logístico se ajustou à curva de progresso da doença. Sijaona \& Mansfield (20), estudando clones de cajueiro, relevaram que o modelo Logístico foi o mais apropriado em classificar os genótipos quanto à resistência genética. Maddison et al. (14), na Tanzânia, também relatam que o modelo Logístico foi adequado em estimar o efeito da sanitização na epidemia do oídio do cajueiro. É sabido que este modelo é muito utilizado em estudos epidemiológicos e as curvas de progresso do oídio obtidas a partir da proteção com o fungicida enxofre, corroboram àquelas obtidas em outros patossistemas $(12,15)$. No entanto, esse modelo não se ajustou ao progresso da doença nas duas épocas no tratamento que não recebeu o controle químico.

No modelo Monomolecular, a taxa de progresso tende a crescer e começa a diminuir à medida que a quantidade de tecido sadio chega ao limite (13). No caso do cajueiro, considerando a ausência de controle, a taxa de progresso da doença aumentou constantemente até o limite de panículas sadias e diminuiu à medida que as panículas tornaram-se completamente infectadas. Para o modelo Logístico, o aumento da taxa é proporcional à quantidade de doença e tecido sadio. No início, a epidemia é baixa, se expande rapidamente e declina quando há diminuição de tecido sadio (13). A interpretação do modelo Logístico para o oídio do cajueiro segue o proposto por Madden et al. (13), onde no início a doença é ausente ou baixa devido à proteção com enxofre; se expande quando finaliza o período protetor (taxa crescente) e diminui a partir do aumento da quantidade de tecido doente (panícula). Neste caso, depois do período de proteção, o aumento da taxa de progresso compensa o baixo nível de inóculo potencial (infectivo) no início da epidemia, como sugerido por Plaut \& Berger (16).

A presença de grande quantidade de inóculo no cajueiro como forma de sobrevivência (17) pode contribuir para a ocorrência de taxas de progresso da doença mais elevadas logo no início da epidemia. A disponibilidade de inóculo, a dispersão e a infecção em órgãos suscetíveis da planta podem influenciar em taxas crescentes de doença (13). Constatou-se que, o aumento rápido da taxa de progresso da doença no clone de cajueiro-anão BRS 189 foi dependente do inóculo inicial. Fato constatado nos tratamentos com e sem proteção de fungicida, onde diferentes modelos foram ajustados de acordo com a disponibilidade de inóculo e tecido disponível para a infecção. Por outro lado, Plaut \& Berger (16) ressaltaram que em outros patossistemas, por vezes, a quantidade de inóculo inicial pode resultar em menor taxa de progresso de doença. Esses resultados provavelmente não se aplicam para o oídio do cajueiro, uma vez que a alta disponibilidade de inóculo presente nos cajueiros próximos à área de cultivo pode ser determinante para o início das epidemias e rápido progresso da doença.

Os modelos matemáticos ajustados revelam que a taxa de progresso da doença é um parâmetro útil para comparar epidemias, inclusive indicando diferenças entre as floradas do clone de cajueiro-anão BRS 189. Através das curvas de progresso é possível estimar a doença de acordo com os modelos gerados. Informações relevantes puderam ser obtidas com as respostas dos modelos que revelaram ser possível diminuir ou retardar as epidemias em campo e até mesmo reduzir as taxas de progresso quando estratégias de controle, como a aplicação de fungicidas à base de enxofre, são adotadas para conter as epidemias do oídio. Os dados de doença visualizados a partir das curvas de progresso também deixam claro o momento em que o controle da doença deve ser iniciado, ou seja, quando os botões florais estão expostos ao fungo e que, nas condições estudadas, é possível determinar até quando há necessidade de aplicação do enxofre para retardar a epidemia e minimizar os danos ocasionados pelo oídio.

\section{AGRADECIMENTOS}

Os autores agradecem aos funcionários da Embrapa Agroindústria Tropical pela colaboração.

\section{REFERÊNCIAS}

1. Aust, H-J.; Hoyningen-Huene, J. Microclimate in relation to epidemics of powdery mildew. Annual. Review. Phytopathology, Palo Alto, v.24, p.491-510, 1986.

2. Bergamin Filho, A.; Amorim, L. Doenças com período de incubação variável em função da fenologia do hospedeiro. Fitopatologia Brasileira, Brasília, v.27, n.6, p.561-565, 2002.

3. Braun, U.; Cook, R.T.A. Taxonomic manual of the Erysiphales (powdery mildews). Ed. CBS Biodiversity Series, n 11, CBS-KNAW Fungal Diversity Centre, Utrecht, The Netherlands 2012. 707p.

4. Campbell, C.L.; Madden, L.V. Introduction to plant disease epidemiology. New York. Wiley-Interscience. 532p. 1990.

5. Cardoso, J.E.; Martins, M.V.V.; Freire, F.C.O.; Viana, F.M.P.; Lima, J.S.; Silva, L.G.C.; Melo, J.G.M. An epidemic outbreak of cashew powdery mildew in Brazil. In: 2014 APS-CPS JOINT MEETING, Minneapolis, Minnesota. Anais. 2014. p.178-O.

6. Cardoso, J.E.; Martins, M.V.V.; Lima, J.S.; Viana, F.M.P.; Silva, L.G.C. Controle químico do oídio do cajueiro. Fortaleza: Embrapa Agroindústria Tropical, 2012. 4p. (Comunicado Técnico, 196).

7. Freire, F.C.O.; Cardoso, J.E.; Santos, A.A.; Viana, F.M.P. Diseases of cashew nut plants (Anacardium occidentale L.) in Brazil. Crop Protection, Guildford, v.21, n.6, p.489-494, 2002.

8. Guzman-Plazola, R.A.; Davis, R.M.; Marois, J.J. Effects of relative humidity and high temperature on spore germination and development of tomato powdery mildew (Leveillula taurica). Crop Protection, Guildford, v.22, n.10, p.1157-1168, 2003.

9. Honorato, T.B.; Lima, J.S.; Cardoso, J.E. Caracterização morfofisiológica e sensibilidade de Pseudoidium anacardii a fungicidas. Fortaleza: Embrapa Agroindústria Tropical, 2016. 25p. (Boletim de Pesquisa e Desenvolvimento, 119).

10. Jeger, M.J. Analysis of disease progress as a basis for evaluating disease management practices. Annual. Review. Phytopathology, Palo Alto, v.42, p.61-82, 2004.

11. Intini, M.; Sijaona, M.E.R. Calendar of disease control with reference to phenological phases of cashew (Anacardium occidentale L.) in Tanzania. Revista di Agricoltura Subtropicale e Tropicale, Firenze, v.77, p.419422, 1983.

12. Liu, N.; Lei, Y.; Gong, G.; Zhang, M.; Wang, X.; Zhou, Y.; Qi, X.; Chen, H.; Yang, J.; Chang, X.; Liu, K. Temporal and spatial dynamics of wheat powdery mildew in Sichuan Province, China. Crop Protection, Guildford, v.74, p.150-157, 2015 
13. Madden, L.V.; Hughes, G.; van den Bosch, F. The study of plant disease epidemics. The American Phytopathological Society (APS PRESS), St. Paul, Minnesota. 421p. 2007.

14. Maddison, A.; Boma, F.; Topper, C.; Shomari, S. Sanitation in the manam gement of cashew powdery mildew disease in Tanzania. In: International Cashew \& Coconut Conference Dar es Salaam, T. Proceedings of the International Cashew and Coconut Conference: trees for life - the key to development: held at Kilimanjaro Hotel, Dar es Salaam, 17-21 February, 1997. Reading, UK: BioHybrids International Ltd. Anais. 1998. p.266-269.

15. Mesquini, R.M.; Schwan-Estrada, K.R.F.; Vieira, R.A.; Nascimento, J.F. Controle e progresso temporal da ferrugem asiática da soja sob controle alternativo em campo. Summa Phytopathologica, Botucatu, v.37, n.1, p.24-29, 2011.

16. Plaut, J.L.; Berger, R.D. Infection rates in three pathosystem epidemics initiated with reduction disease severities. Phytopathology, Saint Paul, v.71, n.9, p.917-921, 1981.

17. Shomari, S.H.; Kennedy, R. Survival of Oidium anacardii on cashew (Anacardium occidentale) in southern Tanzania. Plant Pathology, Oxford, v.48, n.4, p.505-513, 1999.

18. Shomari, S.H.; Kennedy ,R. Field and laboratory investigations on the development of Oidium anacardii in relation to environmental factors. In: International Cashew \& Coconut Conference Dar es Salaam, T. Proceedings of the International Cashew and Coconut Conference: trees for life - the key to development : held at Kilimanjaro Hotel, Dar es Salaam, 17-21 February, 1997. Reading, UK: BioHybrids International Ltd. Anais. 1998. p.260-265.

19. Sijaona, M.E.R.; Mansfield, J.W. Variation in the response of cashew genopypes to the targeted application of fungicide to flower panicles for control of powdery mildew disease. Plant Pathology, Oxford, v.50, n2, p.244-248, 2001

20. Sijaona, M.E.R.; Mansfield, J.W. Studies on cashew resistance to powdery mildew (Oidium anacardii Noack). In: International Cashew \& Coconut Conference Dar es Salaam, T. Proceedings of the International Cashew and Coconut Conference: trees for life - the key to development : held at Kilimanjaro Hotel, Dar es Salaam, 17-21 February, 1997. Reading, UK: BioHybrids International Ltd. Anais. 1998. p.266-269.

21. Sijaona, M.E.R. Studies on aspects of cashew resistance to powdery mildew (Oidium anacardii Noack). 1997. 316f. Tese (PhD in Plant Pathology). London: Department of Biological Sciences, University of London, London.

22. Spósito, M.B.; Bassanezi, R.B.; Amorim, L. Resistência à mancha preta dos citros avaliada por curvas de progresso da doença. Fitopatologia Brasileira, Brasília, v.29, n.5, p.532-537, 2004.

23. Xu, X.M. Effects of temperature on the latent period of the rose powdery mildew pathogen, Sphaerotheca pannosa. Plant Pathology, Oxford, v.48, n.5, p.662-667, 1999 